\title{
La salud pública en tiempos de covid19
}

Es indudable que el año que está por terminar ha sido uno de los peores años que la medicina mundial, nacional y regional ha enfrentado. Esto debido a la pandemia ocasionada por el COVID-19, el cual sigue latente.

Ha sido comprobado una vez más que la fuerza y la adversidad de la naturaleza no puede ser controlada ni domada por el hombre. Nadie imaginó la magnitud del problema ni cómo afrontar esta pandemia del COVID-19. Asimismo, sistemas de salud que eran altamente valorados sucumbieron ante esta crisis sanitaria mundial.

Nosotros como nación tuvimos que hacer frente a la pandemia con un pobre sistema de salud fragmentado, sumado a esto, con crisis y problemas acumulados de años atrás. Esta pandemia se presentó de forma tan rápida que en 2 a 3 meses puso en jaque al mundo. Igualmente, nuestro país y nuestro sistema de salud no se encontraban preparados para responder con prontitud y eficiencia a esta emergencia. Sin embargo, a pesar del déficit en cuanto a recursos humanos, infraestructura y equipamiento, hemos podido salir adelante. Es importante considerar que aún no se puede cantar victoria ni bajar la guardia, pues existe la amenaza de una segunda ola. Si esto llegase a suceder, daremos una mejor respuesta corrigiendo los errores cometidos.

La emergencia sanitaria y la lucha contra el COVID-19 han puesto a nuestro sistema de salud, de cara a una cruda realidad de limitaciones y ausencias imprescindibles para la atención de la población. Por la falta de recursos humanos, no se ha podido atender otras actividades esenciales de salud, tales como control de crecimiento y desarrollo del niño, lucha contra la anemia en la primera infancia y control de gestantes. Esto se refleja en nuestra baja coberturas de vacunación infantil, el incremento de muertes materna y perinatal, así como el control de enfermedades no trasmisibles. Por ejemplo, hipertensión arterial, diabetes, cáncer; además de otras enfermedades transmisibles como tuberculosis, $\mathrm{VIH} / \mathrm{sida}$ y varias otras más que se han manifestado con un aumento de casos nuevos y complicación de los casos controlados. Situación que se presenta como lamentable porque es un retroceso para la salud pública, no logrando así cumplir nuestros objetivos, metas e indicadores de salud.

Quienes hemos vivido emergencias sanitarias en los últimos 40 a 50 años, consideramos a esta como la peor de todas, ya que al margen del problema de salud que compromete el estado anímico de las personas, implica también un costo social y económico muy grande para la nación. Esperamos que los tiempos vividos con el COVID-19, nos sirva de lección para corregir los errores cometidos, para que los ciudadanos seamos más 
responsables con nuestra familia y la sociedad al cumplir con las normas y recomendaciones de salubridad. Este aprendizaje también debe alcanzar a todas las autoridades, cualquiera sea el nivel, para que se otorgue la debida importancia al sector salud. Esto podría lograrse al otorgar un mejor presupuesto y una administración eficiente de la inversión pública sin corrupción. Ese debe ser el compromiso de los futuros gobernantes por el bien de todos los peruanos y de nuestra querida patria, el Perú.

\section{Oscar Galdos Rodríguez \\ Director Regional de Salud Tacna \\ Editor invitado}

\section{Edición:}

Revisión de estilo: El servicio de revisión y ajuste al estilo lingüístico de los artículos originales, reporte de casos y artículos de revisión de la presente edición, estuvo a cargo de la Mag. Roxana Carolina Perca Chagua, según orden de servicio n. ${ }^{\circ} 2321$. 